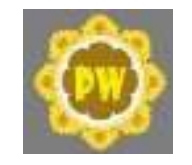

Pratama Widya : Jurnal Pendidikan Anak Usia Dini

Volume 6, No. 1, April 2021

pISSN: 25284037 eISSN: 26158396

https://www.ejournal.ihdn.ac.id/index.php/PW/issue/archive

\title{
PERAN EFIKASI DIRI GURU DALAM PENDIDIKAN ANAK USIA DINI
}

\author{
Oleh : \\ Nyoman Wiraadi Tria Ariani \\ Universitas Hindu Negeri I Gusti Bagus Sugriwa Denpasar \\ e-mail: nyomantria@uhnsugriwa.ac.id
}

Diterima 17 Maret 2021, direvisi 30 Maret 2021, diterbitkan 1 April 2021

\begin{abstract}
Abstrak
Pendidikan Anak Usia Dini adalah pendidikan awal yang memfasilitasi anak untuk mendapatkan stimulasi, bimbingan, pengasuhan, dan pembelajaran yang tepat sehingga kemampuan dan keterampilan anak dapat berkembang dengan optimal. Guru berperan dalam memberikan stimulasi pengasuhan dan pendidikan berkualitas yang diperlukan anak usia dini. Saat guru memberikan pendidikan dan mengembangkan karakter anak, guru memerlukan keyakinan terhadap kemampuan dirinya yang disebut dengan efikasi diri. Efikasi diri merujuk pada keyakinan individu bahwa ia mampu melakukan tugas, dalam hal ini semakin tinggi efikasi dirinya maka semakin yakin atau percaya mampu meraih keberhasilan. Metode penelitian ini berupa kajian pustaka yang mengkaji literatur ilmiah terkait dengan peran efikasi guru dalam Pendidikan Anak Usia Dini. Berdasarkan kajian pustaka, efikasi diri guru dapat dimanfaatkan untuk mengembangkan perilaku inovasi guru dalam pekerjaannya. Guru dengan efikasi diri yang lebih tinggi memperlihatkan tingkat perilaku inovasi yang lebih tinggi. Dengan membangun efikasi diri guru, maka akan berpengaruh pada keyakinan guru saat melakukan tujuan mengajar, mempersiapkan bahan ajar, pola interaksi kelas, peran, praktik kelas dan lain-lain.
\end{abstract}

Kata Kunci: Efikasi Diri, Efikasi Guru, Pendidikan Anak Usia Dini

\begin{abstract}
Early Childhood Education is an early education that facilitates children to get the right stimulation, guidance, nurturing, and learning so that the child's abilities and skills can develop optimally. Teachers play a role in stimulating the quality care and education that early childhood needs. When the teacher provides education and develops the character of the child, the teacher needs confidence in his or her abilities called self-efficacy. Self-efficacy refers to an individual's belief that he is capable of performing tasks, in this case the higher his or her efficacy the more confident or confident he is able to achieve success. This research method is a literature study that examines scientific literature related to the role of teacher efficacy in Early Childhood Education. Based on literature studies, teacher self-efficacy can be used to develop teacher innovation behavior in their work. Teachers with higher self-efficacy showed a higher level of innovation behavior. By building the teacher's self-efficacy, it will affect the teacher's confidence when doing teaching objectives, preparing teaching materials, class interaction patterns, roles, classroom practices and others.
\end{abstract}

Keywords: Self-efficacy, Teacher-efficacy, Early Childhood Education 


\section{PENDAHULUAN}

Menurut data statistik Pendidikan Anak Usia Dini (PAUD) tahun 2018/2019, Indonesia memiliki 201.067 sekolah Pendidikan Anak Usia Dini dengan 656.210 pengajar, serta 6.169.002 siswa (Kementerian Pendidikan dan Kebudayaan Sekretariat Jenderal Pusat Data dan Statistik Pendidikan dan Kebudayaan, 2019). Berdasarkan data tersebut, Indonesia masih sangat membutuhkan pengajar atau guru agar sebanding dengan jumlah siswa yang sangat tinggi. Guru memiliki peranan penting dalam pembangunan pendidikan di Indonesia, terutama guru Pendidikan Anak Usia Dini. Guru Pendidikan Anak Usia Dini berperan membantu membentuk karakter siswa melalui proses pembelajaran dan pengenalan agar anak memahami lingkungan sekitarnya. Selain itu, guru membimbing siswa mengenal potensi, memupuk rasa percaya diri, dan cara membina hubungan atau bersosialisasi dengan orang lain sehingga peran guru Pendidikan Anak Usia Dini sangat penting dalam tumbuh kembang serta masa depan siswa. Hal ini didukung oleh Peraturan Menteri Pendidikan dan Kebudayaan Republik Indonesia Nomor 137 Tahun 2014 tentang Standar Nasional Pendidikan Anak Usia Dini Pasal 7 yang menyatakan bahwa tingkat pencapaian perkembangan siswa dapat dicapai pada rentang usia tertentu melalui Pendidikan Anak Usia Dini.

Pendidikan Anak Usia Dini merupakan pendidikan paling dasar yang bermanfaat untuk mengembangkan sumber daya manusia suatu bangsa sehingga siswa mendapatkan stimulasi, bimbingan, pengasuhan, dan pembelajaran yang dapat mengasah kemampuan dan keterampilan anak sebagai peserta didik atau siswa. Siswa adalah generasi penerus bangsa yang memiliki karakter. Karakter yang kuat suatu bangsa tercermin dalam karakter siswa dan karakter ini diwariskan di setiap generasi melalui proses pendidikan seperti proses pemahaman, komitmen, dan kecenderungan untuk bertindak sesuai dengan nilai-nilai norma serta etika (Milson and Mehlig, 2002). Anak usia dini memiliki kemampuan dan potensi besar yang masih perlu dikembangkan dengan bantuan orang tua dan orang dewasa atau guru (Sujiono, 2009). Oleh karena itu, stimulasi pengasuhan dan pendidikan berkualitas sangat diperlukan anak usia dini karena akan memberikan perbedaan signifikan pada cara anak belajar dan berkembang, yang merupakan modal awal untuk tahap perkembangan selanjutnya (Morrison, 2015).

Pengembangan karakter siswa dibentuk oleh pendidikan yang diberikan sejak dini oleh orangtua, keluarga, dan guru. Selain orangtua dan keluarga, guru merupakan sosok yang sangat berperan dalam tumbuh kembang siswa. Ketika melakukan proses belajar mengajar, guru memiliki kapasitas sebagai pendidik, model, atau teladan bagi peserta didiknya (Sukmawati, 2015). Guru juga berperan sebagai fasilitator siswa agar siswa dapat belajar dan mengembangkan potensi dasar serta kemampuannya secara optimal, dengan demikian guru memiliki peran yang sangat penting dalam pelaksanaan pembelajaran atau pendidikan (Shabir, 2015).

Ketika guru memberikan pendidikan dan mengembangkan karakter siswa, guru memerlukan keyakinan terhadap kemampuan dirinya yang disebut dengan efikasi diri. Efikasi diri merupakan keyakinan akan kemampuan individu untuk memobilisasi motivasi, sumber kognisi, dan tindakan yang diperlukan untuk memenuhi tuntutan situasional yang diberikan (Schmitt dan Highhouse, 2012). Efikasi diri berhubungan dengan keyakinan bahwa diri sendiri memiliki kemampuan melakukan tindakan yang diharapkan (Bandura, 1997). Oleh karena itu, apabila individu memiliki efikasi diri maka individu 
juga memiliki kapasitas melakukan keberhasilan sesuai prosedur, menganggap diri sebagai individu yang efektif yakni individu dapat memecahkan masalah secara efektif, memaksimalkan peluang, dan potensinya serta terus menerus belajar (Daft, 2011).

Efikasi diri memiliki peranan penting dalam pembelajaran (Bandura, 1997). Griffin dan Moorhead (2014) mengungkapkan bahwa efikasi diri dapat meninjau sejauh mana individu percaya dapat mencapai tujuannya bahkan walaupun jika pernah gagal melakukannya di waktu yang lalu. Robbins dan Judge (2013) menyatakan bahwa efikasi diri merujuk pada keyakinan individu bahwa ia mampu melakukan tugas, dalam hal ini semakin tinggi efikasi dirinya maka semakin yakin atau percaya mampu meraih keberhasilan. Oleh karena itu, ketika individu mempunyai efikasi diri atau keyakinan yang tinggi, individu menjadi percaya atau yakin akan adanya kemungkinan keberhasilan dalam mengerjakan tugas-tugas tertentu. Peluang untuk mencapai keberhasilan akan tercapai pada tugas dengan tingkat kesulitan yang lebih tinggi dibandingkan dengan orang yang tidak memiliki efikasi atau dengan efikasi diri yang rendah.

Ada empat proses psikologis dalam efikasi diri, yang pertama proses kognitif yaitu individu yang mempunyai pengertian yang lebih terhadap efikasi akan membayangkan sukses yang memberikan pedoman-pedoman positif dan mendukung untuk mencapai tujuannya. Proses yang kedua adalah motivasi, yakni individu memotivasi diri dan memandu tindakannya yang bersifat antisipatif melalui latihan dari pemikiran sebelumnya. Selanjutnya, ada proses afektif yang mengarah pada kepercayaan individu terhadap kemampuannya dalam mengatasi masalah memegang peranan penting dalam mengatur status emosi. Individu yang percaya bahwa dirinya mampu mengendalikan ancamanancaman tidak akan terganggu pola pikirnya, dan proses yang terakhir adalah proses pilihan, yaitu proses efikasi diri individu dapat mempengaruhi pilihan lingkungannya dan aktivitasnya. Individu akan menghindari situasi dan aktivitas yang dianggap melebihi kemampuannya, demikian pula sebaliknya (Bandura, 1997). Efikasi guru memiliki potensi untuk mempengaruhi lingkungan di sekitar guru seperti saat penerapan praktek pengajaran yang dilakukan di dalam kelas, guru yang memiliki efikasi diri terhadap kemampuannya akan memiliki potensi untuk melakukan beragam variasi pembelajaran. Efikasi guru merupakan faktor penting dalam pembelajaran karena keyakinan guru terhadap kemampuan dirinya mengatur dan melaksanakan tindakan yang diperlukan untuk mencapai keberhasilan dalam tugas pengajaran tertentu (Tschannen-Moran \& Hoy, 2001).

Berdasarkan uraian di atas, maka sangat tepat apabila peranan efikasi guru patut diperhatikan dalam Pendidikan Anak Usia Dini. Menurut penelitian (Gibson \& Dembo, 1984, dalam Milson, 2002), guru yang memiliki efikasi diri yang tinggi cenderung berusaha keras mengajar dengan sebaik-baiknya meskipun berada dalam kondisi yang penuh tantangan. Efikasi diri guru juga berpengaruh pada keberhasilan pengembangan karakter siswa. Guru yang memiliki efikasi tinggi akan kemampuannya mengembangkan karakter siswa memiliki korelasi dengan peningkatan karakter baik pada diri siswa. Sebaliknya, pada guru yang memiliki efikasi rendah cenderung mengalami kegagalan dalam mengembangkan karakter siswa (Milson, 2002; Wynne, 1997).

\section{METODE}

Adapun metode penelitian ini mengkaji mengenai konsep dan teori yang 
digunakan berdasarkan referensi atau literatur yang tersedia, terutama dari artikelartikel yang dipublikasikan dalam berbagai jurnal ilmiah (Sugiyono, 2015). Studi ini merujuk pada penelitian kajian pustaka yang terkait dengan peranan efikasi guru dalam Pendidikan Anak Usia Dini. Peneliti melihat pentingnya efikasi guru dalam Pendidikan Anak Usia Dini, yaitu guru berperan penting membantu membentuk karakter anak melalui proses pembelajaran dan pengenalan agar siswa memahami lingkungan sekitarnya. Guru juga berperan dalam membimbing siswa mengenal potensi, memupuk rasa percaya diri, dan cara membina hubungan atau bersosialisasi dengan orang lain sehingga peran guru Pendidikan Anak Usia Dini sangat penting dalam tumbuh kembang serta masa depan siswa.

\section{PEMBAHASAN}

Schunk (2012) menjelaskan bahwa efikasi diri guru merupakan sebuah prediktor yang signifikan untuk memprediksi prestasi siswa. Efikasi diri guru yang mengacu pada keyakinan-keyakinan guru mengenai kapabilitas yang ia miliki untuk membantu siswa belajar. Efikasi diri guru akan mempengaruhi kegiatan, usaha dan kegigihan guru dalam mendidik siswa (Schunk, 2012). Proses belajar mengajar dapat berlangsung dengan baik apabila guru memiliki kepercayaan diri mengenai kemampuannya dalam mengajar. Guru dengan efikasi yang tinggi percaya apabila mereka melakukan usaha yang lebih besar, maka mereka akan mampu untuk menangani semua siswa, bahkan siswa yang paling sulit (Elsami \& Fatani, 2008).

Pengembangan sekolah dan pengembangan staf sekolah dapat dilakukan dengan cara membangun efikasi diri guru seperti merancang pelatihan guru yang efektif, meningkatkan kompetensi guru dan meningkatkan hasil belajar siswa
(Vadahi dan Lesha, 2015). Hsiao, YaLing, Chang dan Chen (2011) menyatakan efikasi diri guru dapat dimanfaatkan untuk mengembangkan perilaku inovasi guru dalam pekerjaannya. Guru dengan efikasi diri yang lebih tinggi memperlihatkan tingkat perilaku inovasi yang lebih tinggi. Oleh karena itu, apabila upaya membangun efikasi diri guru rutin dilaksanakan, maka akan berpengaruh pada keyakinan guru saat melakukan tujuan mengajar, mempersiapkan bahan ajar, pola interaksi kelas, peran, praktik kelas dan lain-lain. Hal ini senada dengan peran guru sebagai figur teladan yang diatur dalam Undang-Undang (UU) No 14 Tahun 2005 tentang guru dan dosen pasal 10 ayat 1 . Dalam UU No 14 Tahun 2005 ada empat kompetensi yang harus dikuasai oleh guru Pendidikan Anak Usia Dini dan guru secara umum, yaitu kompetensi pedagogik, kompetensi kepribadian, kompetensi sosial dan kompetensi profesional. Kompetensi pedagogik adalah kemampuan mengelola pembelajaran peserta didik, kompetensi kepribadian yaitu guru berakhlak mulia, arif, berwibawa, penuh welas asih, dan murah senyum kepada anak didiknya. Selanjutnya, kompetensi sosial adalah kemampuan guru untuk berkomunikasi dan berinteraksi secara efektif dan efasien baik itu dengan peserta didik, sesama pendidik, orang tua atau wali peserta didik dan masyarakat sekitar dan kompetensi profesional yaitu kemampuan penguasaan materi pelajaran secara luas dan mendalam. Guru mampu merancang, melaksanakan, dan menyusun laporan penelitian dan mengembangkan inovasi untuk masyarakat luas (Wibowo, 2013).

$$
\text { Penelitian Dimopulou }
$$
menjelaskan bahwa efikasi guru sebagai keyakinan guru terhadap kemampuannya dalam mengajar, untuk mengatur dan mempengaruhi para siswa saat proses pembelajaran, sehingga guru mampu memprediksi perkembangan prestasi belajar 
siswa. Efikasi guru berhubungan pada pencapaian siswa. Efikasi yang rendah mengarahkan kepada rendahnya efikasi dan prestasi siswa. Hal senada juga diungkapkan oleh penelitian David dan Kuyini (2012) yang menunjukan bahwa terdapat peran yang positif dari sikap guru dan juga efikasi guru terhadap kesuksesan pelaksanaan pendidikan inklusif bagi siswa yang memiliki kebutuhan khusus. Penelitian ini merujuk pada pengaruh keyakinan guru dalam mengajar pada kelas inklusi, yaitu saat kegiatan proses belajar di kelas seperti pengunaan strategi belajar yang tepat, dapat mendukung pelaksanaan pendidikan inklusif sehingga berdampak pada penerimaan siswa berkebutuhan khusus oleh teman-temannya di kelas.

Guru dengan efikasi diri yang tinggi menjadi lebih bergairah dalam mengajar, siap menerima ide-ide baru dan mampu menggunakan metode pengajaran baru untuk membantu peserta didik dalam belajar dikarenakan guru dengan efikasi yang tinggi tersebut memiliki perilaku mengajar yang positif seperti kesabaran, komitmen dan semangat (Moalosi dan Forcheh, 2015). Efikasi diri dan dukungan sosial guru juga berperan penting dalam memberikan pengaruh pada kematangan karir siswa sehingga siswa termotivasi dan berusaha mengembangkan potensi yang dimilikinya (Fransisca, 2020). Dengan adanya efikasi diri guru maka siswa akan lebih yakin dengan kemampuan dirinya, dengan demikian siswa yang memiliki efikasi diri yang lebih tinggi memiliki kemandirian karir yang lebih tinggi, tekun belajar, dan dalam memotivasi diri (Zakeri dan Shahtalebi, 2014).

Efikasi diri juga berpengaruh langsung positif terhadap kreativitas guru. Hal ini berarti bahwa guru yang memiliki efikasi diri yang tinggi akan dapat meningkatkan kreativitas guru. Efikasi diri dapat dikembangkan melalui upaya guru dalam menguasai kompetensi dan keahlian sesuai dengan bidangnya maupun penguasaan kemampuan dalam pengembangan sistem pendidikan di sekolah sehingga guru mempunyai nilai keyakinan dan percaya diri yang lebih baik. Guru yang mampu meningkatkan efikasi diri dalam proses pembelajaran yang ditandai dengan keyakinan dan penguasaan program pembelajaran di sekolah dapat meningkatkan kreativitasnya dalam pengembangan pembelajaran (Khayati dan Sarjana, 2015). Penelitian Jack, Liu, dan Chiu (2008) juga mengungkapkan bahwa bahwa efikasi yang tinggi akan memberikan pengaruh terhadap hasil ekspektasi guru. Ekspektasi Guru yang yakin akan kekuatan efikasi mereka cenderung terbuka terhadap ide-ide baru, berusaha mencoba metode baru dalam mengajar, dan lebih gigih menghadapi kesulitan dalam kondisi kerja.

$$
\text { Semakin tinggi efikasi diri guru }
$$
maka semakin meningkat tingkat inovasinya. Guru yang memiliki tingkat efikasi diri yang tinggi dalam pembelajaran di sekolah akan memiliki keyakinan dan motivasi yang lebih besar dalam mengembangkan dan memperbarui cara dan metode terkini untuk menciptakan ide dan gagasan baru dalam proses pembelajaran, sehingga inovasi pembelajaran dapat dihasilkan sesuai harapan (Khayati dan Sarjana, 2015). Oleh karena itu, memperbarui kepercayaan mengajar adalah prasyarat inovasi pembelajaran. Guru harus memperbarui keyakinan mereka dan mengadopsi model pengajaran baru untuk memenuhi tuntutan inovasi (Lin, Chuang, dan Hsu, 2014). Dengan demikian dapat dipahami bahwa efikasi diri guru memiliki keterkaitan erat dengan kreativitas dan secara langsung maupun tidak langsung akan berdampak terhadap inovasi yang dilakukan oleh guru dalam sistem pembelajaran di sekolah. 


\section{SIMPULAN}

Peran efikasi diri guru dalam Pendidikan Anak Usia Dini merupakan hal yang penting karena keyakinan guru terhadap kemampuannya sediri akan berdampak pada pengajaran, pendidikan, dan perkembangan siswa. Dengan memiliki efikasi diri maka guru dapat berperan dengan baik sebagai pembimbing yang mendampingi setiap kegiatan yang dilakukan siswa, dan berperan sebagai fasilitator yaitu guru dapat memantau perkembangan siswa sesuai dengan kemampuannya. Dengan keyakinan yang dimiliki guru mengenai kemampuannya maka ia dapat mengatur dan melakukan tindakan yang diperlukan untuk menyelesaikan tugas-tugas, bahkan guru menjadi yakin dapat berhasil melalui tantangan ataupun tugas yang sulit sekalipun.

\section{DAFTAR PUSTAKA}

Bandura, Albert. (1997). Self-Efficacy, The Exercise of Control. New York: W.H. Freeman and Company.

Daft, R. (2011). Leadership Fifth Edition. South Western: Cengage Learning.

David, R., \& Kuyini, A. B. (2012). Social inclusion: teachers as facilitators in peer acceptance of students with disabilities in regular classrooms in Tamil Nadu, India. International Journal of Special Education, 27 (2).

Dimopulou, Evelina. (2012). Self Efficacy and Collective Efficacy Beliefs Of Teacher For Children With Autism. Literacy Information and Computer Education Journal (LICEJ), 3(1).

Elsami, Z. R., \& Fatani, A. (2008). Teachers' sense of self-efficacy, english proficiency, and instructional strategies: a study of nonnative EFL teachers in Iran. Teaching English as a Second or Foreign Language, 11(4).
Fransisca, Suryanto, \& Matulessy. (2020), Efikasi Diri dan Dukungan Sosial Guru dengan Kematangan Karir Siswa. Indonesian Psychological Research, 2(1), 29-38.

Gibson, S., \& Dembo, M.H. (1984). Teacher efficacy: A construct validation. Journal of Educational Psychology, 76 (4), 569-582.

Griffin \& Moorhead. (2014). Organizational: Behavior, Managing People and Organizations. South Western: Cengage Learning.

Hsiao, Ya-Ling, Chang \& Chen. (2011). The Influence of Teachers' Self-efficacy on Innovative Work Behavior. Interpersonal Conference on Social Science and Humanity, IPEDR Vol 5.

Jack, B.M., Liu, Cj. \& Chiu, Hl. (2008). Taiwan Elementary Teachers' Views Of Science Teaching Self-Efficacy And Outcome Expectations. Int $J$ of Sci And Math Educ, 437 (6). Https://Doi.Org/10.1007/S10763008-9126-Y

Kementerian Pendidikan dan Kebudayaan Sekretariat Jenderal Pusat Data dan Statistik Pendidikan dan Kebudayaan, (2019). Pusat Data dan Statistik Pendidikan dan Kebudayaan Kementerian Pendidikan dan Kebudayaan. Jakarta: Kemendikbud.

Khayati \& Sarjana. (2015). Efikasi Diri Dan

Kreativitas Menciptakan Inovasi Guru. Jurnal Pendidikan dan Kebudayaan, 21(3), 243-261.

Lin, M., Chuang, T. \& Hsu, H. (2014). The Relationship among Teaching Beliefs, Student-Centred Teaching Concept and the Instructional Innovation. Journal of Service Science and Management, 7(3), 201210. 
Milson, A.J and Mehlig, L.M. (2002). Elementary School Teachers' Sense Of Efficacy For Character Education. The Educational Research, 96(1), 47-53.

Moalosi, W. T. S., \& Forcheh, N. 2015. SelfEfficacy Levels and Gender Differentials among Teacher Trainees in Colleges of Education in Botswana. Journal of Education and Learning, 4(3), 1-13.

Morrison, G. S. (2015). Pendidikan Anak Usia Dini Saat Ini (13th ed.). Yogyakarta: Pustaka Pelajar.

Peraturan Menteri Pendidikan dan Kebudayaan Republik Indonesia No.137 Tahun 2014 Tentang Standar Nasional Pendidikan Anak Usia Dini Pasal 7 Tentang Standar Tingkat Pencapaian Perkembangan Anak Usia Dini (STPPA).

Robbins \& Judge. (2013). Organizational Behavior. New Jersey: Pearson Education Inc.

Schmitt, N. W., \& Highhouse, S. (2012). Handbook of Psychology, Industrial and Organizational Psychology, Second Edition, Vol 12.

Schunk, Daleh H. (2012). Learning Theories (Teori-Teori Pembelajaran: Perspektif Pendidikan). Yogyakarta: Pustaka Belajar.

Sugiyono, (2015). Metode Penelitian Kuantitatif, Kualitatif, dan $R \& D$. Bandung: Alfabeta.

Sujiono, Yuliani. (2009). Konsep Dasar Anak Usia Dini. Jakarta: Indeks.

Sukmawati, Ati. (2015). Peran Guru dalam Pengembangan Moral bagi Anak Usia Dini. Jurnal Tadris IPA Biologi FITK IAIN Mataram, 8(1).

Tschannen-Moran, M., \& Hoy, A. W. (2001). Teacher efficacy: Capturing an elusive construct. Teaching and Teacher Education, 17(7), 783-805.
U, M. Shabir. (2015). Kedudukan Guru Sebagai Pendidik: (Tugas dan Tanggung Jawab, Hak dan Kewajiban, dan Kompetensi Guru). Jurnal Auladuna, 2(2).

Undang-Undang No 14 Tahun 2005. UNDANG-UNDANG REPUBLIK INDONESIA NOMOR 14 TAHUN 2005 TENTANG GURU DAN DOSEN (kemdikbud.go.id)

Vadahi, F., \& Lesha, J. (2015). Enhancing Teachers Self-Efficacy: Theoretical and Research Considerations. European Scientific Journal, 11(19), 82-89.

Wibowo, Agus. (2013). Pendidikan Karakter Anak Usia Dini (Strategi Membangun Karakter di Usia Emas). Yogyakarta:Pustaka Pelajar.

Wynne, E. A. (1997). For-character education. In A. Molnar construction of (Ed.), The children's character: Ninety-sixth yearbook of the National Society for the Study of Education, part two (pp. 63-76). Chicago: The University of Chicago Press.

Zakeri, S. \& Shahtalebi, B, (2014). Investigate the Relationship Between Job Autonomy And Self Efficacy (Case Study: Technical And Vocational Education Staff Of South Khorasan Province). Journal of Business and Management Review, 4(3), 81-87. 